\title{
Full-Thickness Skin Grafting with De-Epithelization of the Wound Margin for Finger Defects with Bone or Tendon Exposure
}

\author{
Jun Hee Lee, Jin Sik Burm, Sang Yoon Kang, Won Yong Yang \\ Department of Plastic and Reconstructive Surgery, Kyung Hee University School of Medicine, Seoul, Korea
}

Background Full-thickness skin grafts (FISGs) are generally considered unreliable for coverage of full-thickness finger defects with bone or tendon exposure, and there are few clinical reports of its use in this context. However, animal studies have shown that an FSG can survive over an avascular area ranging up to $12 \mathrm{~mm}$ in diameter. In our experience, the width of the exposed bones or tendons in full-thickness finger defects is $<7 \mathrm{~mm}$. Therefore, we covered the bone- or tendon-exposed defects of 16 fingers of 10 patients with FISGs.

Methods The surgical objectives were healthy granulation tissue formation in the wound bed, marginal de-epithelization of the normal skin surrounding the defect, preservation of the subdermal plexus of the central graft, and partial excision of the dermis along the graft margin. The donor site was the mastoid for small defects and the groin for large defects.

Results Most of the grafts (15 of 16 fingers) survived without significant surgical complications and achieved satisfactory functional and aesthetic results. Minor complications included partial graft loss in one patient, a minimal extension deformity in two patients, a depression deformity in one patient, and mild hyperpigmentation in four patients.

Conclusions We observed excellent graft survival with this method with no additional surgical injury of the normal finger, satisfactory functional and aesthetic outcomes, and no need for secondary debulking procedures. Potential disadvantages include an insufficient volume of soft tissue and graft hyperpigmentation. Therefore, FISGs may be an option for treatment of full-thickness finger defects with bone or tendon exposure.

Keywords: Skin / Skin transplantation / Bone / Tendon / Fingers

\author{
Correspondence: Jin Sik Burm \\ Department of Plastic and \\ Reconstructive Surgery, Kyung Hee \\ University School of Medicine, 23 \\ Kyungheedae-ro, Dongdaemun-gu, \\ Seoul 130-872, Korea \\ Tel: +82-2-958-8431 \\ Fax: +82-2-963-5638 \\ E-mail: jsburm@gmail.com
}

This article was presented at the 71st Congress of the Korean Society of Plastic and Reconstructive Surgeons on November 1-3, 2014 in Seoul, Korea and at the Federation of European Societies for Surgery of the Hand Congress 2014 on June 18-21, 2014 in Paris, France.

No potential conflict of interest relevant to this article was reported.

\section{INTRODUCTION}

Full-thickness skin defects of the fingers with exposed bones or tendons can occur through various mechanisms, such as hot press injuries, crushing injuries, chemical injections, deep burns, or abrasion. Since the bone- or tendon-exposed area has poor vascularity, vascularized flaps, including local, regional, distant, and free flaps, have been used to cover full-thickness finger defects $[1-8]$.

Skin grafting is the gold standard for covering skin defects. A full-thickness skin graft (FTSG) results in excellent function after engraftment and should be considered in the reconstruction of functionally and aesthetically important areas like the hands and fingers. However, FTSGs are generally considered unreli- 
able when used over poorly vascularized beds. Therefore, there are few clinical reports of its use in this context, although animal studies have shown that an FTSG can survive over avascular or poorly vascularized defects up to $12 \mathrm{~mm}$ in diameter [9-11].

In our experience, the width of the exposed bones or tendons in full-thickness finger defects is $<7 \mathrm{~mm}$. If the healthy peripheral wound bed is wider than the avascular bone or tendon area, an FTSG will take without serious blood supply issues, since the center of the graft can survive over a bone or tendon area through the bridging phenomenon. Furthermore, the addition of a new well-vascularized bed on the wound margin will increase the possibility of complete graft survival, because a graft centered over an avascular area can survive through the bridging phenomenon $[12,13]$.

The purpose of this report is to present the clinical application of FTSG for covering finger defects with bone or tendon exposure and to describe methods of wound bed and graft preparation that improve graft survival.

\section{METHODS}

The surgical objectives of FTSG for coverage of finger defects with bone or tendon exposure were as follows: healthy granulation tissue formation in the wound bed, marginal de-epithelization of the normal skin surrounding the defect, preservation of the central subdermal plexus of the graft, and tangential excision of the deep dermis along the graft margin (Fig. 1).

Preoperatively, after immobilizing the interphalangeal joints in full extension by inserting a K-wire to the proximal third of the finger to allow motion of the metacarpophalangeal joint, a saline-moistened gauze dressing was applied twice a day for at least seven days, until sufficient healthy granulation tissue filled the wound bed of the soft tissue.

Wound debridement was then performed through tangential excision with a blade or iris scissors. After determining the position of the incision line on the normal skin approximately $3 \mathrm{~mm}$ over the defect margin, the marginal skin was de-epithelized by tangential excision with a blade to provide the graft with a new, healthy vascularized bed (Fig. 1A).

An FTSG was harvested from the mastoid area for small defects and from the groin area for large defects. The mastoid area was the primary donor site because it has compact, well-vascularized tissue. The FTSG was first excised along with subdermal fat tissue. During trimming of the fascia-fat tissue on its undersurface, the subdermal plexus and scanty fat tissues on the central area of the graft, which were used to cover the bone or tendon, were preserved as much as possible (Fig. 2). The deep dermis of the graft along its peripheral margin was excised tangentially with iris scissors. This procedure converted the peripheral graft to a thick split-thickness skin graft, which covered the new vascularized graft bed formed by marginal de-epithelialization (Fig. 1B). We expected that the immediate and complete take of

\section{Fig. 2. Subdermal plexus on the undersurface of the graft}

Graft preparation on the central area of the full-thickness skin graft. The subdermal plexus and scanty fat tissue were preserved on the undersurface of the graft.

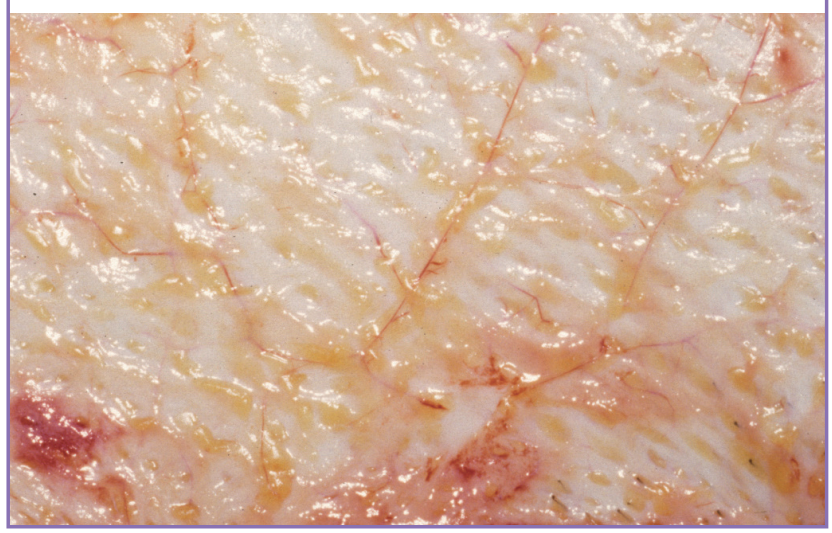

\section{Fig. 1. Schematic diagram of the operative procedure}

Surgical principles of full-thickness skin grafting for full-thickness skin defects of the finger with bone or tendon exposure. (A) Wound bed preparation by tangential excision of granulation tissue and marginal de-epithelization of the normal skin. (B) Coverage of full-thickness skin graft with preservation of the subdermal plexus on the central area and partial excision of the peripheral deep dermis of the graft.
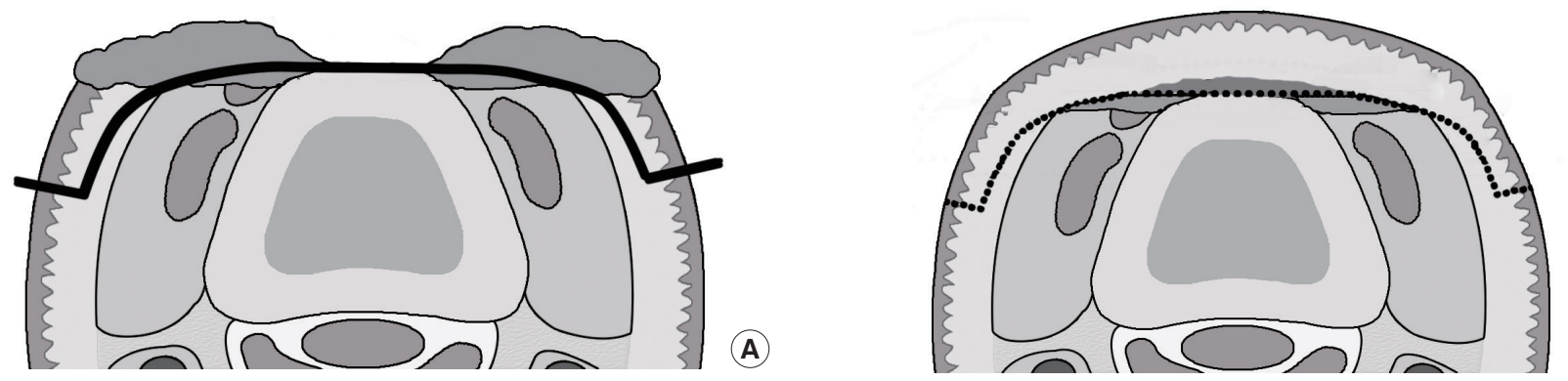
Table 1. Summary of patients with bone- or tendon-exposed finger defects

\begin{tabular}{|c|c|c|c|c|c|c|c|c|}
\hline Case & Sex/Age (yr) & Type of injury & $\begin{array}{l}\text { Site of } \\
\text { defect }\end{array}$ & $\begin{array}{l}\text { Donor } \\
\text { site }\end{array}$ & $\begin{array}{l}\text { Size of graft } \\
\left(\mathrm{cm}^{2}\right)\end{array}$ & $\begin{array}{c}\text { Graft } \\
\text { survival }\end{array}$ & $\begin{array}{l}\text { Follow-up } \\
\quad \text { (mo) }\end{array}$ & $\begin{array}{l}\text { Secondary } \\
\text { deformity }\end{array}$ \\
\hline 1 & Male/26 & Deep burn by hot press & $\begin{array}{l}\text { Dorsal; index, } \\
\text { middle, ring, little }\end{array}$ & Groin & $\begin{array}{l}2.5 \times 5,3 \times 6.5 \\
3 \times 6.5,1.5 \times 3\end{array}$ & Complete & 9 & $\begin{array}{c}\text { Swan neck deformity, } \\
\text { hyperpigmentation }\end{array}$ \\
\hline 2 & Female/66 & Degloving by a cutting machine & Dorsal; middle & Groin & $2 \times 2.5$ & Complete & 3 & Hyperpigmentation \\
\hline 3 & Male/25 & Crushing by high-speed belt & Volar; little, palm & Groin & $\begin{array}{c}3 \times 7 \text { (first) } \\
2 \times 4 \text { (second) }\end{array}$ & $\begin{array}{l}\text { Partial loss } \\
\text { Complete }\end{array}$ & 5 & Hyperpigmentation \\
\hline 4 & Female/40 & $\begin{array}{l}\text { Crushing by jamming-in a } \\
\text { machine }\end{array}$ & Dorsal; index & Mastoid & $1.5 \times 2$ & Complete & 6 & NA \\
\hline 5 & Male/32 & Grinding by electric saw & Dorsal; index & Mastoid & $2 \times 4$ & Complete & 5 & Mallet finger \\
\hline 6 & Female/45 & $\begin{array}{l}\text { Soft tissue necrosis by } \\
\text { chemical injection }\end{array}$ & Dorsolateral; index & Mastoid & $2 \times 3$ & Complete & 3 & Depression \\
\hline 7 & Male/4 & Deep burn by electric spark & $\begin{array}{l}\text { Dorsal; index, } \\
\text { middle }\end{array}$ & Groin & $2 \times 2,1 \times 2$ & Complete & 3 & NA \\
\hline 8 & Female/64 & Deep burn by hot press & $\begin{array}{l}\text { Dorsal; index, } \\
\text { middle, ring }\end{array}$ & Groin & $5 \times 7$ & Complete & 5 & Hyperpigmentation \\
\hline 9 & Female/52 & $\begin{array}{l}\text { Painful nail remnant after } \\
\text { crushing }\end{array}$ & Dorsal; little & Mastoid & $1.5 \times 2.5$ & Complete & 6 & NA \\
\hline 10 & Male/32 & $\begin{array}{l}\text { Contracted nail deformity after } \\
\text { degloving }\end{array}$ & Dorsal; ring & Groin & $2.5 \times 4$ & Complete & 5 & NA \\
\hline
\end{tabular}

the peripheral graft would allow the central graft covering the bone or tendon to take completely through the bridging phenomenon due to the double blood supply, consisting of the subdermal and intradermal vascular plexi.

The donor site was closed primarily. The skin graft was fixed with a simple interrupted suture with 6-0 nylon sutures followed by a simple compressive dressing or a tie-over dressing, which was removed on postoperative day 4 . The wound was then covered with simple compressive dressings and was checked every two or three days for two weeks. The K-wire was removed on postoperative day 14, and active range-of-motion exercise was allowed. A compression hand garment was applied with a topical moisturizer for three to four months. All patients received antioxidants (vitamin $\mathrm{C}$ and $\mathrm{E}$ ) for at least two months to improve graft stabilization and to reduce hyperpigmentation.

\section{RESULTS}

We reconstructed the bone- or tendon-exposed full-thickness defects of 16 fingers of 10 patients (five males and five females) using FTSG (Table 1). The ages of the patients ranged between four and 66 years. The causes of the defects were crushing (three cases), deep burns (three cases), degloving injuries (two cases), electric saw injury (one case), and chemical injection (one case). The defects were on the dorsal side in 15 fingers, and on the volar side in one finger. The donor site was the groin for 12 fingers and the mastoid for four fingers.

All grafts covering the defect of the finger (15 of 16 fingers) survived completely. The peripheral skin of the FTSG took im- mediately in all cases. Grafts over the wide avascular bed were purple in the early phase and progressively became pinkish, as seen in traditional composite grafts, resulting in complete survival. They all achieved good functional and aesthetic results without surgical complications or the need for secondary revision during the follow-up period, which ranged from three to nine months. Static two-point discrimination was evaluated in seven patients and ranged from 10 to $17 \mathrm{~mm}$.

Minor complications included partial graft loss, mild extension deformities, depressions, and hyperpigmentation. Partial graft loss was seen in the central area of the graft in one case (Fig. 3). This patient sustained a severe crushing injury with flexor tendon exposure over nearly the entire volar aspect of the left little finger after jamming the finger in a high-speed rotating belt. The FTSG was partially lost on the poorly vascularized wound bed, and additional grafting was required (Fig. 3A). At five weeks after the first operation, the defect was covered with an FTSG and healed completely. Ultimately, the fifth finger was able to fully extend and flex incompletely at the distal phalangeal joint (Fig. 3B).

Minimal extension deformities were observed in two patients: a mild swan-neck deformity occurred in one patient who had an extensor tendon defect from the distal to the proximal interphalangeal joint (Fig. 4) and a mild mallet finger was observed in one patient who had extensor tendon loss from the distal interphalangeal joint to the middle phalanx (Fig. 5). However, they had no complaints about motion restrictions that interfered with their work and neither required secondary revision or an additional operation during the follow-up period. 


\section{Fig. 3. A 25-year-old man}

(A) The tendon-exposed soft tissue defect of the left fifth finger and the palm after having been jammed in a high-speed rotating belt. (B) Partial graft loss at five weeks after full-thickness skin grafting. (C) The fifth finger extended in the full range of motion five months after secondary grafting. (D) Flexion of the fifth finger was limited but satisfactory given the severity of the injury.
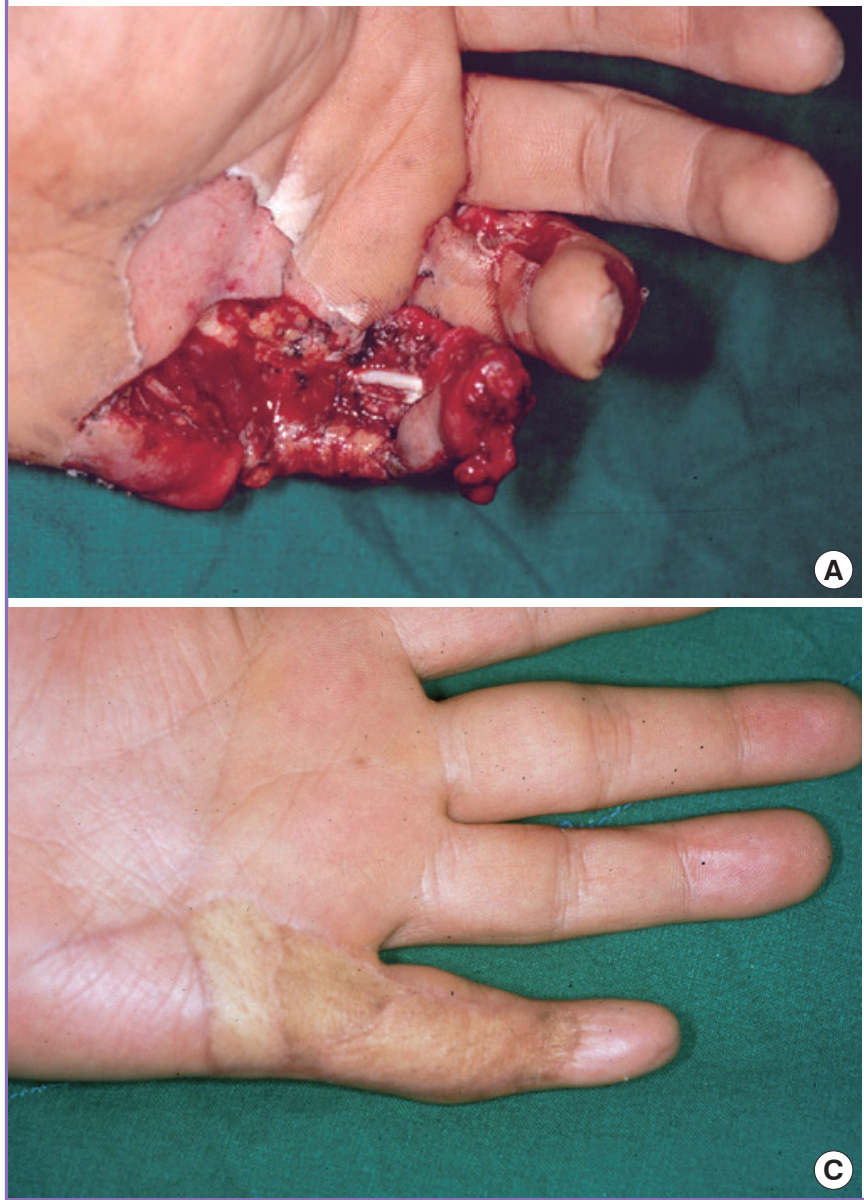

A graft depression deformity occurred due to subcutaneous tissue deficiency despite complete graft survival in one patient who sustained wide soft tissue necrosis of the right index finger after a chemical injection. At the three-month follow-up, there was significant improvement in the graft depression, but a mild depression remained. The patient refused an additional operation for soft tissue augmentation.

Some degree of graft hyperpigmentation occurred in most cases, especially in areas with wide exposure, but progressively improved. At the last follow-up, hyperpigmentation was still present in four patients who had undergone FTSG from the groin. The mastoid grafts were much less pigmented than the groin grafts.

\section{DISCUSSION}

The finger is a very compact, multi-structural, and complex organ, including multiple bones, joints, tendons, ligaments, and fat
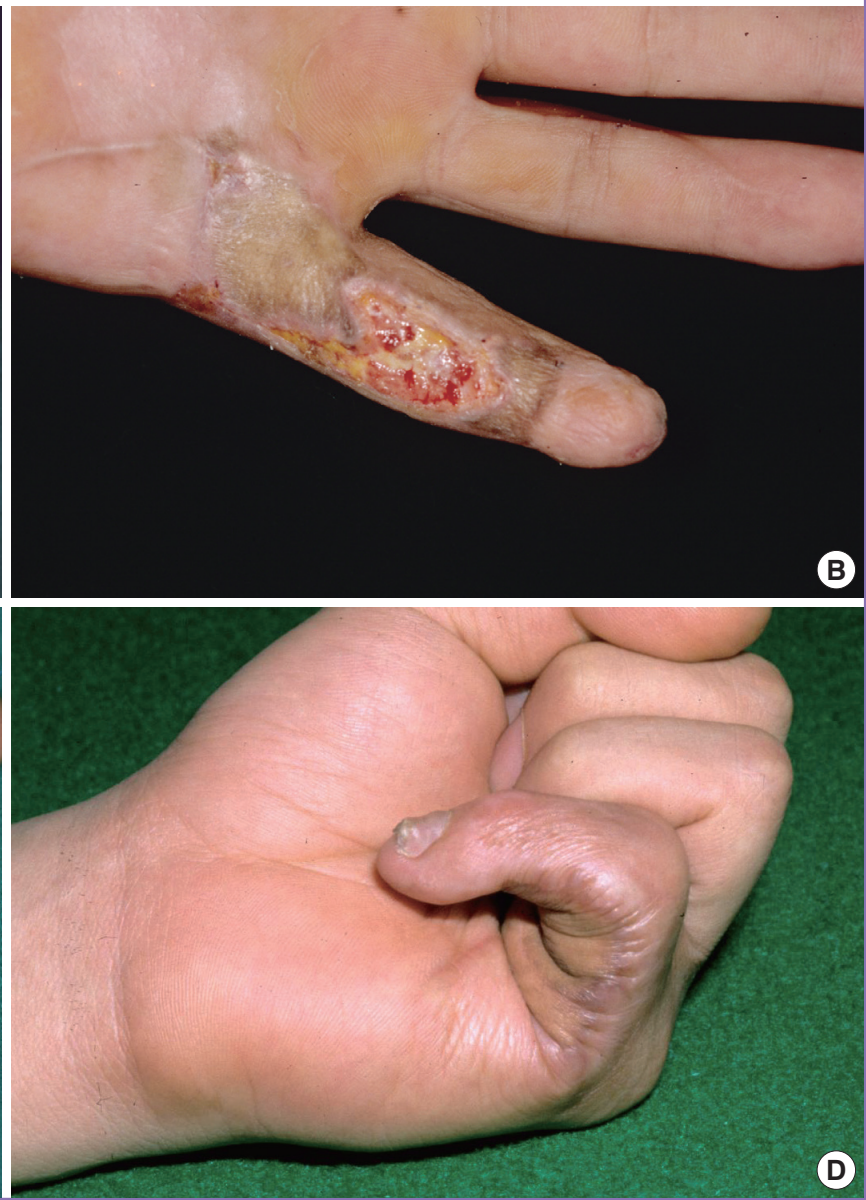

tissue. Thus, it can be difficult to select appropriate soft-tissue coverage for full-thickness skin defects of the fingers with bone or tendon exposure.

Generally, various types of flaps, including local, regional, and free flaps, have been used to cover small or moderate size fullthickness defects of the fingers [1-5]. Flaps have several advantages, including sufficient soft tissue volume and a good blood supply, but also have some disadvantages, including bulkiness and donor morbidity.

In local and regional flaps, including the adipofascial turn-over flap [2], reverse homodigital island flap [3], cross finger flap [4], and reversed dorsal metacarpal flap [5], additional surgical injury of the normal structures of the fingers or the hand near the defect is inevitable, especially when the defects are of moderate size, as in our series, resulting in various types of donor morbidity of the hand.

A free flap, such as an arterialized venous flap [6] or a thin skin flap $[7,8]$, is an excellent treatment choice for covering multiple 


\section{Fig. 4. A 26-year-old man}

(A) The bone-exposed defects of the right second to fifth fingers with extensor tendon loss after a contact burn due to a hot press injury. (B) Preoperative wound preparation with tangential excision and marginal de-epithelialization. (C) The full-thickness skin graft completely survived four days after grafting from the groin. (D) A very satisfactory result was obtained at nine months after surgery, but a mild swan-neck deformity was shown at the third and fourth fingers.
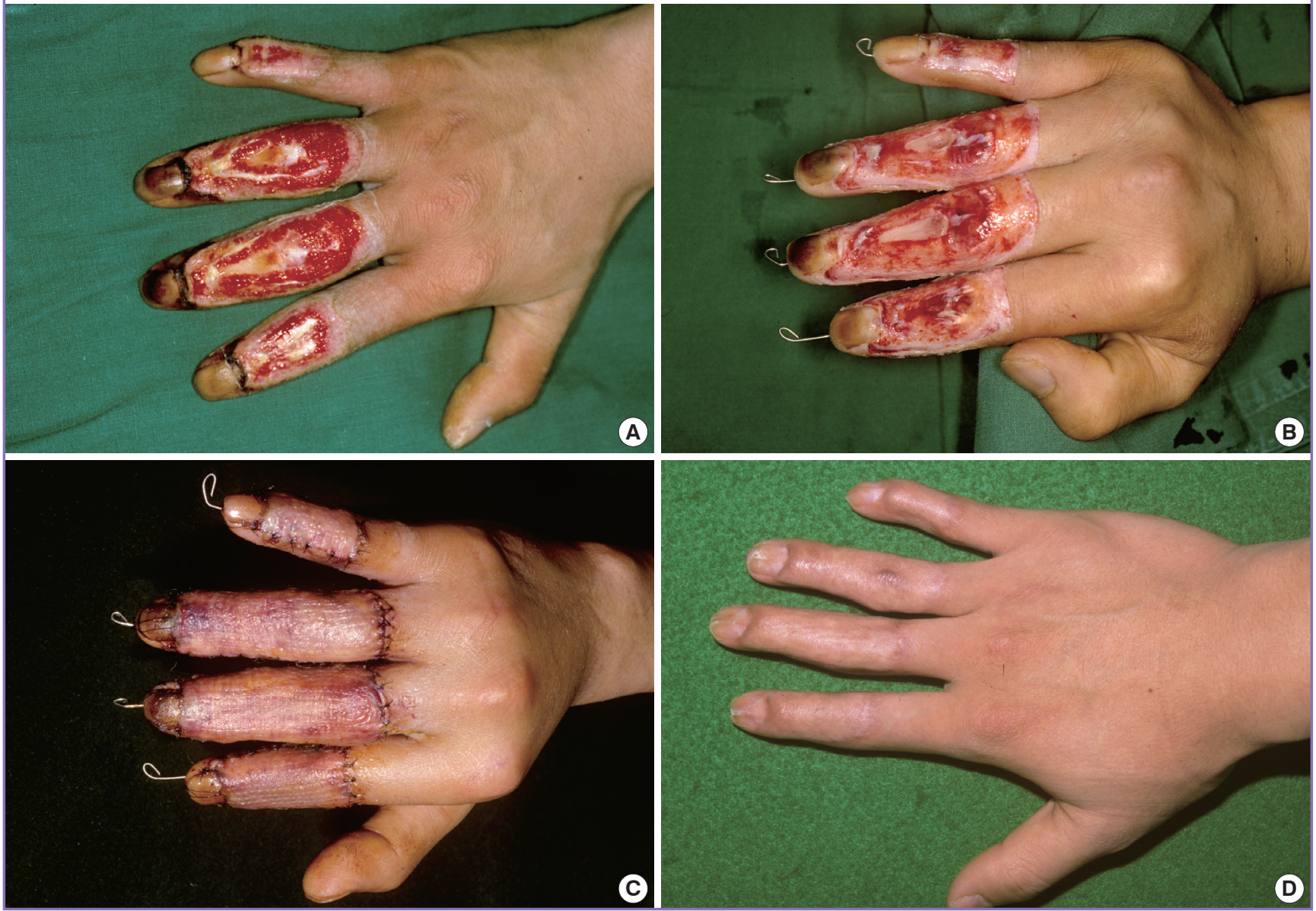

Fig. 5. A 32-year-old man

(A) A bone-exposed defect on the dorsum of the right second and third finger with extensor tendon loss following injury with an electric saw. (B) A satisfactory result was obtained at six months after full-thickness skin grafting from the groin, but mild mallet finger was observed in the index finger.
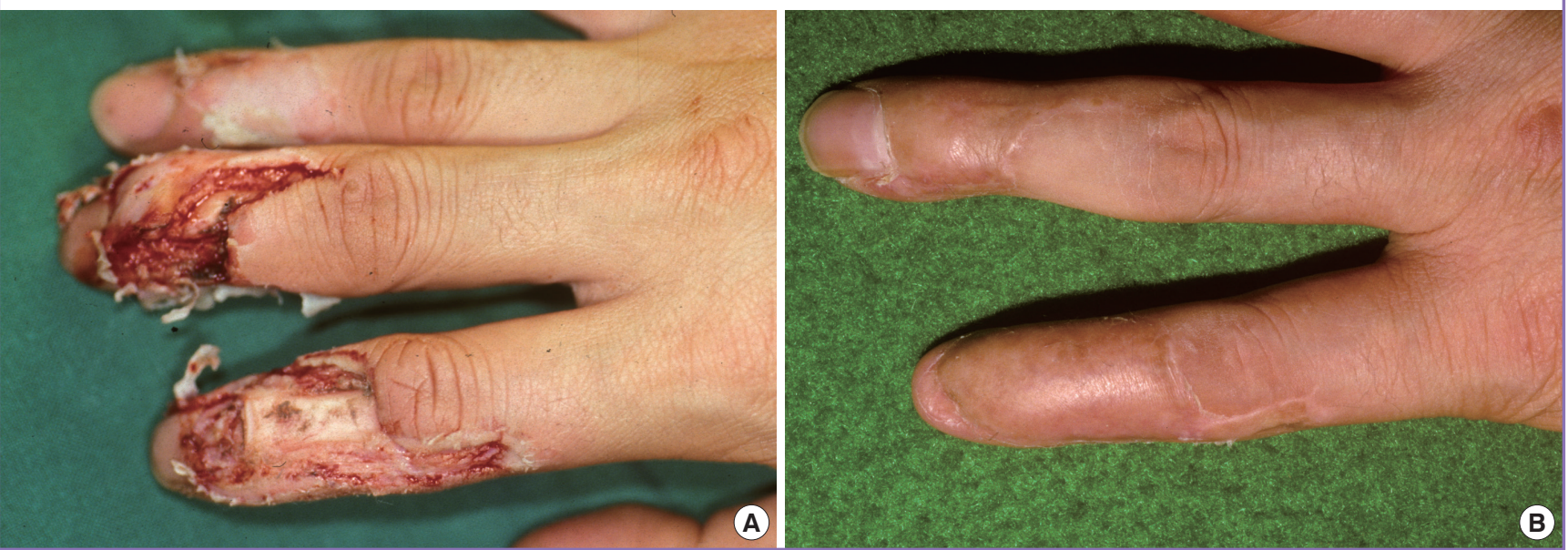
or wide dorsal defects of the finger without additional surgical injury of the surrounding normal hand. However, these techniques have some disadvantages, such as a long operation time, flap bulkiness, and the need for secondary revision. The venous free flap is a good option for a small or moderate dorsal defect with minimal donor morbidity, but requires a lengthy microvascular technique along with close observation and does not result in improved sensory recovery compared to that achieved with an FTSG. A toe free flap is indicated only for small volar defects. The thin free flap can be thinned down to 3- to 4-mm thickness, but it still looks bulky if it is on the dorsal finger [8]. The bulkiness of these flaps can hamper range of motion and function of the fingers as well as worsen the external appearance, which may be a serious problem for some patients, especially for women [14].

The FTSG shows excellent function after engraftment and therefore should be considered in the reconstruction of functionally important areas like the hands and fingers. It has several advantages: it is a simple procedure, easily applied to various defect types and sizes, it does not involve additional structural damage of the normal finger surrounding the defect, it is a onestage operation, it creates adequate thickness for the dorsal skin without bulkiness, there is no need for secondary revision, and it results in minimal donor morbidity. Although FTSGs have many advantages, they are generally considered unreliable over poorly vascularized beds because of concerns about incomplete take or graft loss.

Clinical and animal studies have shown that small bridges of skin grafts survive over small avascular defects [9-13]. FTSGs contain an intact vascular system with horizontally arranged networks of intradermal and subdermal plexi [15]. The circulation can be restored to the FTSG using a smaller number of vascular anastomoses to the recipient site [15,16]. Gingrass et al. [10] demonstrated revascularization of FTSGs on the bare cartilage of rabbit ears, and concluded that FTSGs can survive over an avascular or poorly vascularized defect up to $12 \mathrm{~mm}$ wide, including 90\% graft survival over a silicone sheet $8 \mathrm{~mm}$ in diameter. In our experience, the width of the exposed bones or tendons of the full-thickness defects of the fingers is $<7 \mathrm{~mm}$. If a good vascular bed along the periphery of the defect is prepared, the peripheral FTSG will take completely and result in subsequent complete survival of the central FTSG over the avascular area of the bone or tendon through the bridging phenomenon. For this reason, we utilized FTSGs to cover bone- or tendon-exposed full-thickness defects of fingers in this series.

The key procedures for achieving complete graft survival over avascular areas are marginal de-epithelization of the normal skin along the defect margin and partial excision of the deep dermis along the peripheral margin of the FTSG. The goal of the former procedure is to provide each defect margin with a new, healthy dermal bed that has rich vascularity. The goal of the latter procedure is to change the FTSG to a thick split-thickness skin graft. These two procedures induce prompt marginal revascularization of the peripheral graft and induce complete graft take on the new healthy bed, resulting in complete survival of the central graft over the poorly vascularized bed by the bridging phenomenon.

The center of the graft contained the subdermal vascular plexus and a small amount of subdermal fat tissue surrounding the vascular plexus and covering the bone- or tendon-exposed areas (Fig. 2). It is supported by a dual blood supply through the intradermal and subdermal plexus horizontally from the early-revascularized peripheral graft, not vertically from the avascular wound bed, resulting in a high probability of complete graft survival [12]. In addition, the subdermal fat tissue may play a role in soft tissue augmentation on the exposed bone and allow tendon gliding similar to what is observed in a thin skin flap.

In this series, FTSGs were harvested from the groin or mastoid area, depending on the defect size. The mastoid skin has compact dermoadipofascial tissue with rich intradermal and subdermal vascular networks. Its skin rigidity ensures that postoperative shrinkage of the graft is minimal $[12,13]$. The graft skin from the mastoid is less pigmented postoperatively than skin from the body and the extremities. For this reason, we prefer the mastoid to the groin as a donor site. The maximal width of an FTSG that can be harvested from the mastoid, allowing for primary closure of the donor defect, is $2 \mathrm{~cm}$.

The extension system of the fingers is dependent on the interplay between the long extensor tendon, two lateral bands from the interosseous muscle tendons, the dorsal expansion hood, the interosseous and long extensor slip, and the triangular ligament, unlike the flexion system with its two longitudinal flexor tendons. It is commonly accepted that moderate or large defects of the extensor tendons should be reconstructed with a tendon graft. In most of our cases, however, there was a small or moderate defect of the extensor tendon associated with bone or joint exposure, which was not repaired with a tendon graft. During preoperative wound care and the few weeks after skin grafting, a dense fibrotic sheet of scar tissue on the entire wound bed and below the FTSG inevitably forms and adheres to the remaining long extensor tendon, lateral band, and their supporting ligaments, resulting in maintenance of structural continuity of the extension system. Because the dorsal scar sheet was constructed when the interphalangeal joints, with or without the metacarpophalangeal joint, were fully extended, this may keep the finger extended in the resting state. Nevertheless, the fibrotic scar 
sheet can be stretched and loosened somewhat by repeated finger flexion, inducing an extension deformity, such as a mallet or swan neck deformity. In this series, however, we observed far fewer of these deformities than we anticipated, and they did not require additional treatment. Therefore, we concluded that a subcutaneous dorsal scar sheet formed in the fully extended position during approximately three weeks of wound care and that skin grafting played some role in repairing the extension system of the finger.

FTSGs demonstrated excellent function after engraftment and should be considered in the reconstruction of functionally and aesthetically important areas like the hands and fingers. We applied FTSGs to cover full-thickness skin defects of the finger with bone or tendon exposure. The surgical principles that increased the graft survival rate were healthy granulation tissue formation on the wound bed, marginal de-epithelization of the normal skin, preservation of the central subdermal plexus of the graft, and tangential excision of the deep dermis along the graft margin. Most of the grafts had complete survival, with the exception of one case with partial graft loss. Despite other minor complications, including minimal extension deformities, depressions, and hyperpigmentation, this method showed excellent graft survival, no surgical injury of the normal finger, and satisfactory functional and aesthetic outcomes without the need for debulking procedures. Therefore, FTSG may be a valuable option for covering full-thickness finger defects with bone or tendon exposure.

\section{REFERENCES}

1. Khouri RK, Badia A. Reconstructive surgery of individual digits (excluding thumb). In: Mathes SJ, Hentz VR, editors. Plastic surgery. Vol. VII. Philadelphia: Saunders; 2006. p.207-52.

2. Lai CS, Lin SD, Yang CC, et al. The adipofascial turn-over flap for complicated dorsal skin defects of the hand and finger. Br J Plast Surg 1991;44:165-9.
3. Bene MD, Petrolati M, Raimondi P, et al. Reverse dorsal digital island flap. Plast Reconstr Surg 1994;93:552-7.

4. Lee NH, Pae WS, Roh SG, et al. Innervated cross-finger pulp flap for reconstruction of the fingertip. Arch Plast Surg 2012;39:637-42.

5. Dautel G, Merle M. Dorsal metacarpal reverse flaps: anatomical basis and clinical application. J Hand Surg Br 1991; 16:400-5.

6. Woo SH, Kim KC, Lee GJ, et al. A retrospective analysis of 154 arterialized venous flaps for hand reconstruction: an 11year experience. Plast Reconstr Surg 2007;119:1823-38.

7. Cho YJ, Roh SY, Kim JS, et al. Second toe plantar free flap for volar tissue defects of the fingers. Arch Plast Surg 2013; 40:226-31.

8. Kim SW, Jung SN, Sohn WI, et al. Ulnar artery perforator free flap for finger resurfacing. Ann Plast Surg 2013;71:72-5.

9. Rees TD, Ballantyne DL Jr, Hawthorne GA, et al. Effects of silastic sheet implants under simultaneous skin autografts in rats. Plast Reconstr Surg 1968;42:339-42.

10. Gingrass P, Grabb WC, Gingrass RP. Skin graft survival on avascular defects. Plast Reconstr Surg 1975;55:65-70.

11. Wright JK, Brawer MK. Survival of full-thickness skin grafts over avascular defects. Plast Reconstr Surg 1980;66:428-32.

12. Burm JS, Hansen JE. Full-thickness skin grafting with marginal deepithelialization of the defect for reconstruction of helical rim keloids. Ann Plast Surg 2010;65:193-6.

13. Burm JS. Reconstruction of the nasal tip including the columella and soft triangle using a mastoid composite graft. J Plast Reconstr Aesthet Surg 2006;59:253-6.

14. Lin TS, Jeng SF, Chiang YC. Resurfacing with full-thickness skin graft after debulking procedure for bulky flap of the hand.J Trauma 2008;65:123-6.

15. Smahel J, Clodius L. The blood vessel system of free human skin grafts. Plast Reconstr Surg 1971;47:61-6.

16. Zarem HA, Zweifach BW, McGehee JM. Development of microcirculation in full thickness autogenous skin grafts in mice. Am J Physiol 1967;212:1081-5. 